\title{
Zinc of unsuspected worth
}

\author{
Elements that are widespread in nature and have been used for thousands of years are not typically \\ deemed exciting, but Anders Lennartson argues that we shouldn't take zinc for granted.
}

\section{A} professor once told me "You'll never impress me with zinc". Why are certain elements more spectacular than others? And why should zinc not be one of these? Sure, it does not exhibit extensive redox chemistry: zinc(I) species are rare, and calculations have recently suggested that we will never see a stable zinc(III) compound ${ }^{1}$. Element 30 holds on tightly to its $d$ electrons, which is why its compounds do not display the vivid colours we have grown accustomed to with $d$-block elements. Actually, owing to their filled $d$ shells, zinc and the other group 12 elements aren't strictly speaking 'transition' elements - they are sometimes referred to as post-, or 'honorary', transition metals.

We do not know who first discovered zinc $^{2,3}$, but zinc compounds have been used since ancient times; the Romans mixed zinc ores with charcoal and copper to produce brass. Its volatility, however, prevented its isolation until the Middle Ages and zinc was probably first obtained in India, whereas commercial production first occurred in China. Among chemists, it did not receive much interest until the eighteenth century, but from then it was soon found to be quite important: zinc protects countless tons of iron from rusting, it serves as a cathode in zinc-carbon and alkaline batteries, its oxide found its way into sunscreens, and zinc chloride is used as a flux for soldering.

Furthermore, element 30 is essential for human life; each of us contains about two grams of zinc. As numerous transcription factors and enzymes feature zinc ions in their cores, we would simply not survive a day without it - carbonic anhydrase, alcohol dehydrogenase and insulin protease are three enzymes that rely on the Lewis acidity of zinc. A well-known structural motif is the 'zinc fingers', where zinc ions both help fold peptide chains and provide a site for substrate coordination.

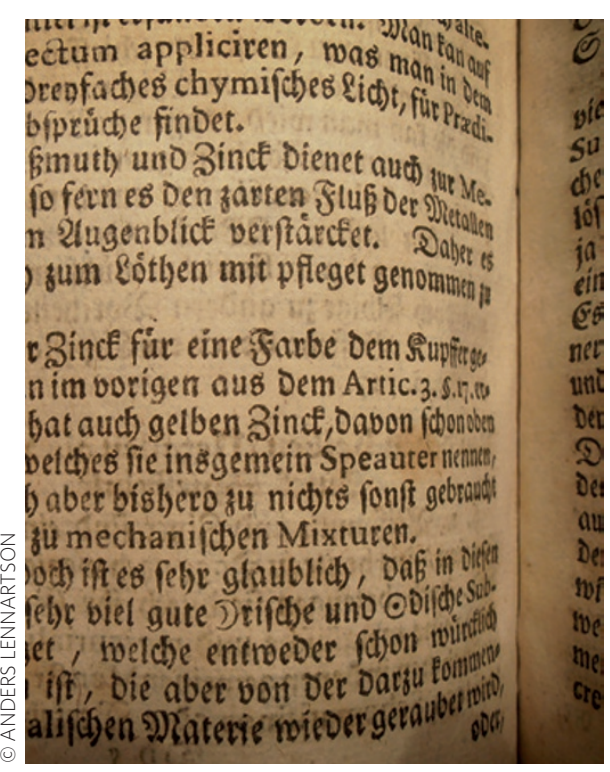

Organic chemists also use their share of zinc. In 1849, Edward Frankland heated ethyl iodide with zinc powder in a sealed glass tube, with the idea of isolating free ethyl radicals ${ }^{4,5}$. To his surprise, he found that on adding a drop of water to the product, a blue-green flame of several feet shot out from the tube. Diethylzinc, the first main-group organometallic compound, was discovered! This essentially marked the birth of organometallic chemistry - in 1830, William Christopher Zeise had reported the compound $\mathrm{K}\left[\left(\mathrm{CH}_{2}=\mathrm{CH}_{2}\right) \mathrm{PtCl}_{3}\right] \mathrm{H}_{2} \mathrm{O}$, known as Zeise's salt, but it had only received modest attention. Diethylzinc inflames spontaneously in air and as dry nitrogen or argon were not readily available in those days, the brave pioneers of organometallic chemistry often used hydrogen as an inert gas; not exactly my first choice when working with pyrophoric substances...

The applications of organozinc compounds have ranged from attempts to prevent old documents from degrading by treatment with diethylzinc vapour (it actually works, but nobody dares to use the method!) to the Nobel Prize-winning use of organozinc derivatives in crosscoupling reactions. Organozinc reagents are typically milder and more selective than the popular magnesium-based Grignard reagents, and in recent years more and more complex functionalized organozinc reagents have been prepared ${ }^{6}$.

An unusual example of selectivity in organozinc chemistry is the Soai reaction, described in 19957. Dialkylzincs do not react with aldehydes without a catalyst; in the presence of a catalyst, however, diisopropylzinc reacts with prochiral pyrimidyl carboxaldehydes to give chiral alcohols. The reaction is autocatalytic, meaning that the product (a pyrimidyl alcohol) can catalyse its own formation. This is not bad in itself, but what makes this reaction unique is that the pyrimidyl alcohol produced will have a greater optical activity than the original catalyst. In effect, the catalyst can not only favour the formation of one optical isomer, but it also suppresses the formation of the opposite isomer. The small statistical bias in a virtually racemic catalyst is enough to trigger this amplification.

Based on its organometallic reactivity alone - how is zinc not impressive?

ANDERS LENNARTSON is at

Chalmers University of Technology,

Department of Chemical and Biological

Engineering, Polymer Technology, 41296

Gothenburg, Sweden.

e-mail: anle@chalmers.se

\section{References}

1. Schlöder, T., Kaupp, M. \& Riedel, S. J. Am. Chem. Soc. 134, 11977-11979 (2012)

2. Weeks, M. E. Discovery of the Elements 6 th edn (Journal of Chemical Education, 1956)

3. Gmelins Handbuch der Anorganischen Chemie. Zink, System-nummer 32 8th edn (Verlag Chemie, 1924) 4. Seyferth, D. Organometallics 20, 2940-2955 (2001).

5. Frankland, E, Experimental Researches in Pure, Applied, and Physical Chemistry (John van Voorst, 1877).

6. Knochel, P. et al. in Chemistry of Organozinc Compounds (eds Rappoport, Z. \& Marek, I.) 287-393 (Wiley, 2006). 7. Soai, K. et al. Nature 378, 767-768 (1995)
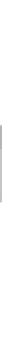